\title{
Validity and Reliability of Measurement Instrument for Sport Motivation Scale in Professional Athletes in Team Sports of Iran
}

\author{
Jasem Manouchehri*, Farshad Tojari and Sahar Soltanabadi \\ College of Physical Education and Sport Sciences, Central Tehran Branch, Islamic Azad University, Tehran, Iran
}

\begin{abstract}
Motivation represents one of the most important variables in sport. A large number of studies incorporating the SDT framework in the sport domain have confirmed that SDT is appropriate to understanding and promoting optimal motivation in sport. The purpose of this study was to determine the validity and reliability of sport motivation questionnaire. For selecting our sample we use available random sampling, so 200 participants were randomly selected for both male and female of professional athletes on the field of volleyball team, basketball, football, handball, futsal and then completed the questionnaires in a voluntary manner. Cronbach's alpha was used to calculate the reliability and confirmatory factor analysis test was used for studying the validity of the questionnaire. Findings showed that a Cronbach's alpha level for sport motivation was 0.80 , which indicates the reliability of the variable is relatively good. And it should be mentioned that Sport motivation scale models used in society of professional athletes of Iranian team was relevant.
\end{abstract}

Keywords: Sport motivation; Professional athletes; Confirmatory factor analysis

\section{Introduction}

Regular play and practice of sport activities is associated with a number of positive outcomes, including increased fitness, increased vitality, increased self-esteem, and reduced serious illness [1,2]. Although most people to some extent are aware of the positive outcomes associated with sport activity, many people discontinue their sport participation every year [3]. Accordingly, a significant amount of research has been conducted on motivation in sport for the purpose of understanding why some athletes show an enduring desire to pursue their sport, whereas others quit or lose interest [4]

Motivation and its impact on behavior can be well expressed by self-determination theory which developed by Deci and Ryan [5]. Selfdetermination theory is a macro theory about human motivation that is associated with the development and function of personality in social contexts. The theory analyzes a behavior in which to what the extent human behavior is voluntary or autonomic behavior [5]. Motivation represents one of the most important variables in sport. In fact coaches and athletes agree that motivation is one of the key elements that will facilitate not only performance but also a positive experience in the sport area [6]. A large number of studies incorporating the SDT framework in the sport domain have confirmed that SDT is appropriate for understanding and promoting optimal motivation in sport [7].

Early sport motivation measurement instrument did not adequately measure all types of motivation as explained by SDT and/or presented weak factor structures [e.g. [8,9]]. The original authors of the Sport Motivation Scale (SMS; Pelletier et al.) progresses measurement in contextual sport motivation based on self-determination theory [5]. Since 1995, the SMS has been used extensively in sport motivation research. However, research has identified several limitations of the SMS -theoretically, empirically, and practically. We developed the SMS-6 in response to increase evidence that the SMS required revision, by including four items measuring integrated regulation, replacing of four problematic items, and constructing a composite intrinsic motivation subscale [6].

Mallett et al. [10] stated that sport motivation scale which had been developed earlier should be revised to include a criterion for measuring integrated regulation. Because without this criterion, the scale does not reflect all existing structures within the frame work of selfdetermination theory. Mallett et al. also argued that some cases should be removed from the scale and subscale of intrinsic motivation should be combined in a single measuring criterion. Sport motivation scale have been used in some studies such as studies by [10-14] Kawabata and Mallett [15]. According to the growing interest in studies in the field of sport motivation, a valid measurement instrument is required. So the purpose of this study was determining the validity and reliability of measurement instrument of sport motivation in professional athletes in team sports of Iran.

\section{Materials and Methods}

\section{Participants}

The population of this research consist of all professional athletes in team sports (for both men and women) who have competed at least 5 years in volleyball, basketball, futsal, handball, football. The sample consisted of 200 participants who were randomly selected among available sports. They included 114 men and 86 women. The average of age and standard deviation for the men were 22.51 and 4 respectively and those indicators for the women were v23.31, 3.56 respectively that both of the groups completed questionnaires in voluntary manner.

\section{Measurements instrument}

Sport Motivation Scale developed by Mallett et al. [10] Motivation is an internal factor that stimulates individual's behavior and leads to a specific direction and coordinates it. Motivation is turning to specific

*Corresponding author: Jasem Manouchehri, College of Physical Education and Sport Sciences, Central Tehran Branch, Islamic Azad University, Tehran, Iran, Tel: 989126628481; E-mail: Manouchehri.jasem@gmail.com

Received July 28, 2014; Accepted February 12, 2015; Published February 21 2015

Citation: Manouchehri J, Tojari F, Soltanabadi S (2015) Validity and Reliability of Measurement Instrument for Sport Motivation Scale in Professional Athletes in Team Sports of Iran. J Psychiatry 18: 253 doi: 10.4172/2378-5756.1000253

Copyright: ( 2015 Manouchehri J, et al. This is an open-access article distributed under the terms of the Creative Commons Attribution License, which permits unrestricted use, distribution, and reproduction in any medium, provided the original author and source are credited 
Citation: Manouchehri J, Tojari F, Soltanabadi S (2015) Validity and Reliability of Measurement Instrument for Sport Motivation Scale in Professional Athletes in Team Sports of Iran. J Psychiatry 18: 253 doi: 10.4172/2378-5756.1000253

Page 2 of 4

activity and continued it; that may be a physical activity or mentalsocial activity that is measured by sport motivation scale with 7 item Like rt scale. This scale consists of 24 statements and six subscales that include:

\section{A motivation}

This means lack of purpose and intentionality in one's action.

\section{External regulation}

Which refers to doing actions for obtain rewards or avoid blame by others?

\section{Introjected regulation}

This refers to behaviors that are strengthened through internal pressures such as guilt or anxiety.

\section{Identified regulation}

That is when person emphasize on behavior and give worth to that behavior.

\section{Integrated regulation}

This represents the most independent form of extrinsic motivation that happens when there is heterogeneity between behavior rules and needs, goals and personal confirmed values which are part of the person.

\section{Intrinsic motivation}

This means engaging in an activity for itself and for the pleasure and satisfaction derived from participation. Four statements were used for each subscales and for responding to each statement, is used 7 item Like rt scale that range from: completely disagree with degree (1) and completely agrees with the degree (7). The English form of the questionnaire of doping behavior was translated into Persian by specialist and then scale of validity was confirmed by experts in that field. In research by Mallett et al. [10] reliability of questionnaires by counting reliability of Cronbach's alpha coefficient was obtained up to 0.70 In this research Cronbach's alpha coefficient for sport motivation obtain 0.80 .

\section{Statistical methods}

Statistical methods in this study were both descriptive and inferential statistics. Mean, standard deviation, and frequency tables for summarizing and classifying the raw data were used in descriptive and Cronbach's alpha was used in inferential statistics for calculating validity. Confirmatory factor analysis was used to test the validity of the questionnaire and SPSS software (version 16) was used for data analysis.

\section{Results and Discussion}

Results showed that 162 participants among the 200 participant114 were male and 86 were female- believed that their success in future depends on the their success in sports but 38 women did not believe that their success in future depends on the their success in sports..

Table 1 show descriptive indicators such as mean and standard deviation for all question of sports motivation questionnaire. Findings in Table 1 indicate that Question 2 of intrinsic motivation subscale has highest mean $(M=5.54)$ and Question 4 has the lowest mean $(M=4.85)$. Also, Question 4 of intrinsic motivation subscales has highest standard deviation $(\mathrm{SD}=1.80)$ and its second question has the lowest $\mathrm{SD}(\mathrm{SD}=1.57)$. Question 2 of introjected regulation subscales has the highest mean $(M=5.19)$ and its third question has the lowest mean $(\mathrm{M}=4.26)$. Moreover question 3 of introjected regulation subscales has the largest $\mathrm{SD}(\mathrm{SD}=1.90)$ and its second question has the lowest standard deviation $(\mathrm{SD}=1.59)$. Question 4 of identified regulation

\begin{tabular}{|c|c|c|c|}
\hline Statements & distinctive & SD & Mean \\
\hline For the excitement I feel when I am really involved in the activity. & IM 1 & 1.94 & 4.87 \\
\hline Because I feel a lot of personal satisfaction while mastering certain difficult training techniques & IM 2 & 1.57 & 5.54 \\
\hline For the satisfaction I experience while I am perfecting my abilities. & IM 3 & 1.60 & 4.94 \\
\hline For the pleasure of discovering new performance strategies & IM 4 & 1.80 & 4.85 \\
\hline Because it is absolutely necessary to do sports if one wants to be in shape & INR 1 & 1.75 & 5.10 \\
\hline Because I must do sports to feel good about myself & INR 2 & 1.59 & 5.19 \\
\hline Because I would feel bad if I was not taking time to do it & INR 3 & 1.90 & 4.26 \\
\hline Because I must do sports regularly & INR 4 & 1.83 & 4.30 \\
\hline Because it is a good way to learn lots of things which could be useful to me in other areas of my life & IDR 1 & 1.63 & 4.86 \\
\hline Because it is one of the best ways I have chosen to develop other aspects of my life. & IDR 2 & 1.46 & 4.90 \\
\hline Because it is one of the best ways to maintain good relationships with my friends. & IDR 3 & 1.79 & 4.87 \\
\hline Because training hard will improve my performance & IDR 4 & 1.57 & 5.25 \\
\hline Because it allows me to be well regarded by people that I know & ER 1 & 1.71 & 4.05 \\
\hline For the prestige of being an athlete & ER 2 & 1.93 & 3.95 \\
\hline For the material and/or social benefits of being an athlete & ER 3 & 2.07 & 4.11 \\
\hline To show others how good I am at my sport. & ER 4 & 1.85 & 4.21 \\
\hline Because it's part of the way in which l've chosen to live my life. & IR 1 & 1.88 & 4.45 \\
\hline Because it is an extension of me. & IR 2 & 1.72 & 5.01 \\
\hline Because participation in my sport is consistent with my deepest principles & IR 3 & 1.78 & 4.58 \\
\hline Because participation in my sport is an integral part of my life. & IR 4 & 1.71 & 4.97 \\
\hline I don't know anymore; I have the impression of being incapable of succeeding in this Sport. & AM 1 & 1.76 & 2.41 \\
\hline I don't know if I want to continue to invest my time and effort as much in my sport anymore & AM 2 & 1.61 & 2.72 \\
\hline It is not clear to me anymore; I don't really think my place is in sport. & AM 3 & 1.35 & 1.97 \\
\hline I don't seem to be enjoying my sport as much as I previously did & AM 4 & 1.69 & 2.31 \\
\hline
\end{tabular}

Table 1: Describes the mean and standard deviation in questions of the sport motivation scale 
Citation: Manouchehri J, Tojari F, Soltanabadi S (2015) Validity and Reliability of Measurement Instrument for Sport Motivation Scale in Professional Athletes in Team Sports of Iran. J Psychiatry 18: 253 doi: 10.4172/2378-5756.1000253

Page 3 of 4

subscales has highest mean $(M=5.25)$ and its first question has the lowest mean $(\mathrm{M}=4.86)$ and question 3 of identified regulation subscales has the highest standard deviation $(\mathrm{SD}=1.79)$ and its second Question has the lowest standard deviation ( $\mathrm{SD}=1.46)$. In addition, question 4 of external regulation subscale has highest mean $(\mathrm{M}=4.21)$ and its second question has the lowest mean $(\mathrm{M}=3.95)$ and Question 3 of external regulation sub scale has the highest standard deviation $(\mathrm{SD}=2.07)$ and its first question the lowest standard deviation $(\mathrm{SD}=1.71)$. The question 2 of integrated regulation subscale has the highest mean $(M=5.01)$ and its first question has the lowest mean $(\mathrm{M}=4.45)$ and question 1 of integrated regulation subscale has the highest standard deviation $(\mathrm{SD}=1.88)$ and its fourth Question has the lowest standard deviation $(\mathrm{SD}=1.71)$. Question 2 of a motivation subscale has the highest mean $(\mathrm{M}=2.72)$ and its third question has the lowest mean $(\mathrm{M}=1.97)$. Also, question 1 of a motivation subscale has the highest standard deviation $(\mathrm{SD}=1.76)$ and its third question has the lowest standard deviation $(\mathrm{SD}=1.35)$.

Results of Table 2 show the Cronbach's alpha coefficients for the sport motivation variables. Table 3 shows Cronbach's alpha coefficients for dimension of sport motivation.

Table 4 shows measurement instrument of sport motivation in standardized estimate. Factor loadings of model in standardized estimate show the effect of each variable or statements in explanation of variance of scores in variable or main factor. For example, factor loading in question 1 in intrinsic motivation is 0.58 In other words; the first question can explain almost $34 \%$ of the variance in intrinsic motivation. The amount 0.66 is amount of error. Table 4 also show significantly of coefficient and obtained parameters of measurement model of intrinsic motivation variable that show all the coefficients are significant. The scores of test which are greater than 1.96 or less than -1.96 indicate significantly of relationships (Table 5).

Goodness of fit statistics like (chi-square $=456.95$ ), which compare to the degrees of freedom 194 is less than the number 3, which indicate very acceptable Goodness of fit. According to the achieved results, we observed that the Cronbach's alpha coefficient for sport motivation was 0.80 which indicates good reliability (Table 2 ). Cronbach's alpha for the other dimension of sports motivation was shown at an acceptable level, except identified regulation and a motivation subscales that were relatively in weak level, and also with the removal of Question 1 of intrinsic motivation subscale and question 4 of a motivation subscale, Cronbach's alpha increased (Table 3). In study by Veskovic and Milanovic [11], Cronbach's alpha of identified regulation and

\begin{tabular}{|c|c|}
\hline Variable & Sport motivation \\
\hline$\alpha$ & 0.805 \\
\hline Omitted Question & - \\
\hline Final $\alpha$ & - \\
\hline
\end{tabular}

Table 2: Cronbach's alpha coefficients for the variables of study

\begin{tabular}{|c|c|c|c|c|c|c|}
\hline Variable & Intrinsic Motivation & Integrated Regulation & Identified Regulation & External Regulation & Amotivation & Introjected Regulation \\
\hline$\alpha$ & 0.718 & 0.781 & 0.686 & 0.790 & 0.676 & 0.717 \\
\hline Omitted Question & 1 & - & - & - & 4 & - \\
\hline Final $\alpha$ & 0.732 & - & - & - & 0.752 & - \\
\hline
\end{tabular}

Table 3: Cronbach's alpha coefficients for dimension of the sport motivation

\begin{tabular}{|c|c|c|c|c|}
\hline & & Factor load & Error & Significance Coefficient \\
\hline \multirow{3}{*}{ Intrinsic Motivation } & IM2 & 0.58 & 0.66 & 8.25 \\
\hline & IM3 & 0.79 & 0.38 & 12.12 \\
\hline & IM4 & 0.70 & 0.51 & 10.37 \\
\hline \multirow{4}{*}{ Integrated Regulation } & IR1 & 0.66 & 0.57 & 9.79 \\
\hline & IR2 & 0.79 & 0.38 & 12.41 \\
\hline & IR3 & 0.59 & 0.65 & 8.55 \\
\hline & IR4 & 0.76 & 0.42 & 11.84 \\
\hline \multirow{4}{*}{ Identified Regulation } & IDR1 & 0.67 & 0.55 & 10.18 \\
\hline & IDR2 & 0.62 & 0.62 & 9.16 \\
\hline & IDR3 & 0.50 & 0.75 & 7.22 \\
\hline & IDR4 & 0.58 & 0.67 & 8.46 \\
\hline \multirow{4}{*}{ External Regulation } & ER1 & 0.66 & 0.57 & 9.43 \\
\hline & ER2 & 0.77 & 0.40 & 11.57 \\
\hline & ER3 & 0.68 & 0.54 & 9.76 \\
\hline & ER4 & 0.67 & 0.55 & 9.65 \\
\hline \multirow{3}{*}{ Amotivation } & AM1 & 0.87 & 0.25 & 12.66 \\
\hline & AM2 & 0.63 & 0.60 & 8.91 \\
\hline & AM3 & 0.64 & 0.60 & 8.97 \\
\hline \multirow{4}{*}{ Introjected Regulation } & INR1 & 0.53 & 0.72 & 7.07 \\
\hline & INR2 & 0.63 & 0.60 & 8.71 \\
\hline & INR3 & 0.68 & 0.54 & 9.52 \\
\hline & INR4 & 0.67 & 0.56 & 9.29 \\
\hline
\end{tabular}

Table 4: The results of measurement model of sport motivation 
Citation: Manouchehri J, Tojari F, Soltanabadi S (2015) Validity and Reliability of Measurement Instrument for Sport Motivation Scale in Professional Athletes in Team Sports of Iran. J Psychiatry 18: 253 doi: 10.4172/2378-5756.1000253

Page 4 of 4

\begin{tabular}{|c|c|}
\hline AGFI & 0.92 \\
\hline GFI & 0.95 \\
\hline NFI & 0.95 \\
\hline RMSEA & 0.083 \\
\hline
\end{tabular}

Table 5: Goodness of fit statistics of model

integrated regulation was obtained 0.65 rules, and other subscaleswere obtained above 0.70. In study by Barghi Moghaddam et al. [12] on 176 teenage soccer players, alpha for sport motivation variable obtained 0.71 , respectively. In this study, the results of factor loading analysis indicated that all statements have been in order to assess the main variables. And in general, the validity and reliability of the scale was acceptable. The study by Kawabata et al. [15] which conducted with aims to reassess the factor structure of the Sport Motivation Scale with 24 statements over 437 participants; confirmatory factor analysis model compare to the sample data was not good enough. Through the evaluation of solving the exploratory structural equation modeling, it was found that two factors are loaded poorly on non-target parameters. Confirmatory factor analysis model which was modified by removing the two factors satisfactorily became acceptable for data of study and all 6 factors became different adequately.

\section{Conclusions}

According to this issue that motivation is indicator of one of the most important variables in sport and also, the measurement instrument of motivation did not measure, at first, all kinds of explained motivation in self-determination theory in adequate and qualified way; Or presents weak factor structures; Mallett et al. developed Sports Motivation Scale-6 in 2007. The aim of the present study has been determining Validity and reliability of the measurement instrument of sport motivation in professional athlete of team sport of Iran and according to the results, itseems that spot motivation scale has been a valid and reliable scale in assessing the scale of the sport motivation for athletes. Moreover, the sport motivation scale model which used in the society of professional athletes in Iranian team sport was appropriate and all statements of sports motivation scale were significantly related to the mentioned variable. The overall result of this study is the Persian form of the sport motivation scale is equivalent to the English form, and it covers the basic concepts. For the future researches, it is recommended to use other statistical methods such as retest method for determining their liability of used tools in present study and try to compare the results of both studies.

\section{References}

1. Bouchard C, Blair S, Haskell W (2007) Physical activity and health. Champaign, IL: Human Kinetics.

2. Pelletier L, Vallerand R, Sarrazin $P$ (2007) Measurement issues in selfdetermination theory and sport. In N. Chatzisarantis, M. Hagger (Eds.), intrinsic motivation and self-determination in exercise and sport IL:Human Kinetics.

3. Sarrazin P, Boiché J, Pelletier L (2007) A self-determination theory approach to dropout in athletes. In M. S. Hagger, \& N. L.D Chatzisarandis (Edn), intrinsic motivation and self-determination in exercise and sport Champaign, Illinois: Human Kinetics.

4. Pelletier L, Rocchi M, Vallerand R, Deci E, Ryan R (2013) Validation of the revised sport motivation scale (SMS-II). Psychology of Sport and Exercise.

5. Deci EL, Ryan RM (1985) Intrinsic Motivation and Self-determination in Human Behavior, Plenum, New York, NY.

6. Vallerand R (2004) Intrinsic and extrinsic motivation in sport.

7. Vallerand $R$ (2007) Intrinsic and extrinsic motivation in sport and physical activity: a review and a look at the future. In G. Tennenbaum, R. Eklund, Handbook of sport psychology (3rdedn.) New York: John Wiley \& Sons.

8. McAuley E, Duncan T, Tammen V (1989) Psychometric properties of the intrinsic motivation inventory in a competitive sport setting: a confirmatory factor analysis. Research Quarterly for Exercise and Sport, 60.

9. Weiss M, Brademeir B, Shewchuk R (1985) An intrinsic/extrinsic motivation scale for the youth'sport setting: a confirmatory factor analysis. Journal of Sport Psychology, 7.

10. Mallett C, Kawabata M, Newcombe P (2007) Progressing measurement in sport motivation with the SMS-6: A response to Pelletier, Vallerand, and Sarrazin. Psychology of Sport and Exercise, 622-631.

11. Vesković A, Milanović M (2011) Relationship between goal orientation, motivation and positive affective outcomes of young athlete in serbia. Physical Education and Sport 9: 455-464.

12. Barghi Moghaddam J, Salehian M, Hashem Kandi Asadi R, Dorostkar Ruhan N (2012) Relationship between identity styles with motivation factors and success feeling among soccer players. Euro J Exp Bio 2: 769-773.

13. Aghdasi M, Nasiri M (2012) Motivations and to Identify its Relationship with Socioeconomic Conditions of Male and Female Participants in Public Exercises in the City of Tabriz. World Appl Sci J 17: 109-112.

14. Paige Pope J, Wilson P (2012) Understanding Motivational Processes in University Rugby Players: A Preliminary Test of the Hierarchical Model of Intrinsic and Extrinsic Motivation at the Contextual Level. International Journal of Sports Science \& Coaching 7: 1 .

15. Kawabata M, Mallett C (2013) Examining discriminant validity issues of the sport motivation Scale-6. Journal of Sport Sciences 312: 173-180. 